Valeria Bordone \& Bruno Arpino

\title{
Grandparenthood, grandchild care and depression among older people in 18 countries
}

\begin{abstract}
Due to the increasing central role of grandparenthood in later life, sound knowledge about its effects on older people's health is more and more important. This paper examines the impact of becoming a grandparent, having more grandchildren, and engaging in grandchild care on depressive symptoms. Moreover, based on the structural ambivalence theory, we expect that such effects differ across contexts as (grand)childcare is differently organised across Europe. Taking advantage of the longitudinal structure of the Survey of Health, Ageing and Retirement in Europe (SHARE), we estimate fixed-effects models. Our results show that women face a decline in depressive symptoms when becoming grandmothers, but neither an increase in the number of grandchildren nor changes in grandchild care are associated with changes in depressive symptoms. The analyses by country highlight differences across Europe, without, however, drawing a clear pattern. Our results show that depression consequences of grandparenthood also vary between countries characterised by similar roles of grandparents. This suggests the need to make available more refined questions about grandparenthood in surveys on older people.
\end{abstract}

Key words: grandparenthood, grandchild care, depression, Europe.

\section{Introduction}

As a consequence of the socio-demographic changes in terms of increasing longevity, decreasing fertility, and postponement of childbearing, the role of grandparents has become more and more a central feature of later life (Leopold/Skopek 2015; Margolis 2016). Its benefits have been shown, in line with the active ageing framework (WHO 2002; Zaidi et al. 2013), mainly in terms of engagement in grandchild care as an activity that positively affects health and subjective wellbeing (e.g., Arpino et al. 2018; Arpino/Bordone 2014; Di Gessa et al. 2016). In this study, we extend the knowledge in this field by investigating whether the broader concept of grandparenthood (including becoming a grandparent, having additional grandchildren, and changes in the engagement in grandchild care) affects older people's mental health. In particular, we analyse changes in depressive symptoms 
by relying on longitudinal data from the Survey of Health, Ageing and Retirement in Europe (SHARE). Depression has been estimated to be the fourth leading cause of the global burden of disease (Ustün et al. 2004), it is the second leading cause of disability worldwide (Ferrari et al. 2013) and is expected to become the leading cause of disability in later life by 2030 (Kok et al. 2012). Such a debilitating condition, characterised by the presence of specific symptoms as anxiety, insomnia, fatigue and a number of psychosomatic disorders that can be triggered by biological, psychological and socio-economic factors, places a substantial burden in terms of public health systems and beyond, to include decline in the quality of life, increased risk of heart disease and stroke, worsening overall health status, and earlier mortality (Blazer 2003; Gallagher et al. 2012). The importance of studying depression rests also on its influence on health behaviours (e.g., Kuo et al. 2011) and other health measures (e.g., Moussavi et al. 2007).

The association between social support and mental health is well established in the literature (e.g., Dalgard et al. 1995; McCabe et al. 1996). It is usually hypothesised that altruistic behaviours and (balanced) intergenerational exchanges are beneficial to mental health (Fujiwara/Lee 2008; Hayslip/Kaminski 2005). Yet, grandchild care can also be stressful and might limit participation in other activities. This, in turn, might negatively impact on health (Jendrek 1993; Szinovacz et al. 1999).

Our contribution is threefold. First, we investigate the effect of grandparenthood on depression by accounting for the multidimensionality of the concept of grandparenthood. In doing so, we test whether such an effect is driven by becoming a grandparent (i.e., grandparenthood per se), an increase in the number of grandchildren, and provision of grandchild care. Moreover, we add to previous literature (e.g., Brunello/Rocco 2019; Di Gessa et al. 2016) by considering more waves of the same dataset, and investigating gender differences. To the best of our knowledge, only one study so far examined the effect of the transition to grandparenthood on grandparents' depression (Condon et al. 2018), based however on one single country (Australia) and a small sample (262 female and 168 male grandparents). Second, we explore the role of context in the association between grandparenthood and depression. As the grandparental role varies across countries (Bordone et al. 2017; Hank/Buber 2009), the effect of grandparenthood on depression may also vary. This heterogeneity could be related to the broader cultural context (i.e., norms and values), as well as to the institutional setting (i.e., policies and, more in general, welfare regimes) in which grandparents and grandchildren are embedded. Previous studies on this topic have mostly relied on a single country (e.g., Condon et al. 2018; Grundy et al. 2012) or pooled together data from different countries (e.g., Di Gessa et al. 2016). Third, from a methodological point of view, we examine the effect of grandparenthood on depression using fixed-effects models. Previous studies in the related literature have often employed cross-sectional data, with a few exceptions that investigated the effect of grandchild care on health outcomes drawing on longitudinal data (Chung/Park 2018; Di Gessa et al. 2016; Grundy et al. 2012). To our knowledge, only Ates (2017) relied on fixed-effects models to study whether grandchild care affects self-reported health. By using fixed-effects models we can exploit the longitudinal dimension of SHARE data and additionally account for time-invariant unobserved confounders. 


\section{Background}

An increasing number of studies have been investigating the impact of grandparenthood on grandparents' health and wellbeing. Despite mainly and consistently focusing on grandchild care as the central activity linked to the grandparental role, such literature has shown mixed results. Scholars have emphasised positive consequences of caring for grandchildren on grandparents' lifestyle (Waldrop/Weber 2001), physical health and healthy behaviours (Di Gessa et al. 2016; Hughes et al. 2007), and better cognitive functioning (Arpino/Bordone 2014). Yet, also negative consequences of grandchild care have been found for grandparents' physical health (Grinstead et al. 2003; Minkler/FullerThomson 1999). These heterogeneous effects might depend on the variety of outcomes under study, but also on the degree of involvement of grandparents in grandchild care (Coall/Hertwig 2011) and on the cultural context (Neuberger/Haberkern 2014). Furthermore, the multidimensionality of the concept of grandparenthood has rarely been considered. An exception is the work by Bordone and Arpino (2016) on the association of grandparenthood per se and of grandchild care with subjective age.

\section{Grandparenthood and depression}

A wide array of studies within the literature on grandparents have investigated mental health consequences of grandchild care on grandparents. Studies from the USA showed that grandparents (and grandmothers in particular) raising grandchildren tend to report a higher likelihood to elevated depressive symptomatology when compared with grandparents who live apart from grandchildren or grandparents living in multigenerational households (Blustein et al. 2004; Fuller-Thomson/Minkler 2001; Musil et al. 2009; Musil et al. 2013). Similarly, custodial grandmothers experience depressive symptoms at a higher rate than the general population of women of the same age (Whitley et al. 2016). However, the stress associated with day-to-day efforts of raising grandchildren coupled with the family situations that require grandparents to take on primary care to grandchildren might explain such elevated depression risk compared to non-custodial/non-caregiver grandparents.

By contrast indeed, grandmothers who co-reside in a multigenerational home with grandchildren and the grandchildren's parents typically report different stresses than noncaregivers or those raising grandchildren, for example because of the parents' personal situation (e.g., job loss, financial problems, divorce, single or teen parenthood). Yet, grandmothers in multigenerational homes usually receive more instrumental support, and may also be less likely to experience depressive symptoms (Musil et al. 2009).

Research on supplementary grandchild care in the USA has mainly found a positive association between looking after grandchildren and grandparents' mental health. In particular, cross-sectional investigations provided evidence of less depressive symptoms for grandparents engaged in grandchild care (Blustein et al. 2004; Minkler et al. 1997). Also, studies that considered changes in the provision of grandchild care found that grandparents who recently started providing grandchild care or continued to provide non-intensive care reported fewer depressive symptoms, compared with grandparents who were not providing such care (Hughes et al. 2007). Similar evidence was found for Taiwan (Ku et 
al. 2013) and for Chile (Grundy et al. 2012), with the latter study using longitudinal data but not focussing on changes in childcare provision.

These results would suggest us to hypothesise that looking after grandchildren reduces depressive symptoms. Yet, by considering a shorter panel of the same dataset that we are using and adjusting for baseline depression, Di Gessa et al. (2016) found a nonsignificant association between the provision of any grandchild care and subsequent depressive symptomatology in Europe as a whole. A non-significant effect was also recently found by Ates (2017) who investigated whether supplementary grandchild care influences grandparents' self-rated health (SRH) in Germany. Although focusing on a different outcome, he has used the same methodology as in our study (i.e., fixed-effects approach). While his results showed a positive (albeit small) association between supplementary grandchild care and SRH in random effects models, the fixed-effects model showed that the intrapersonal change in grandchild care was not associated with a change in grandparents' SRH. This suggests that studies using a between-variation approach might overestimate the influence of grandchild care on grandparents' health because they do not control for unobserved (time-constant) heterogeneity.

Finally, Brunello and Rocco (2019) using two waves of the same data we employ found that provision of grandchild care was associated with an increase in grandparents' depression.

Despite the mixed results from previous literature, empirical evidence so far mainly suggests not to expect negative effects of grandparental childcare on depressive symptoms of grandparents.

Only a few studies have considered the consequences of being a grandparent per se as compared to the effect of taking an active caregiving role. As mentioned above, Condon et al. (2018) is the only study that did so while investigating depression. They found that the transition to grandparenthood was not associated with depression, while contacts with and provision of care to grandchildren reduced depressive symptoms. Yet, other studies considered related outcomes. For example, Danielsbacka and Tanskanen (2016) showed that being a grandparent is not associated with either higher or lower happiness among older Finns. Arpino et al. (2018) reached similar conclusions for life satisfaction, using data on several European countries. Christiansen (2014) found a higher mortality risk for grandfathers (but not grandmothers) as compared to their grandchildless counterparts in Norway.

Drawing on this evidence, we could therefore expect a null effect of the transition to grandparenthood and of an increase in the number of grandchildren on depressive symptoms. This might be a compound outcome of positive experiences coming with grandparenthood, including emotional closeness and strengthened generational ties (Silverstein et al. 1998), as well as of negative perceptions, such as an older feeling (Barak/Gould 1985) and an overwhelming role (Kaufman/Elder 2003) corresponding, for example, to a higher number of grandchildren.

The heterogeneous findings of the literature so far might be due to the need to account for the degree of involvement in grandchild care (Coall/Hertwig 2011), and for the cultural context (Neuberger/Haberkern 2014). Furthermore, as one could notice in our literature review, most of the studies mentioned focused on grandmothers or did not distinguish between grandmotherhood and grandfatherhood. According to Hank and colleagues (2018), 
who recently discussed the promising avenues that research on intergenerational relationships might take in the future, there is a need to analyse grandparenthood and grandchild care by taking a gender perspective. We therefore carry out our analyses on becoming a grandparent, increasing number of grandchildren, and grandchild care separately for women and for men, and by country.

\section{The role of context}

Previous studies have analysed how contextual factors shape the role of grandparents as providers of grandchild care. Two broad factors have been so far examined: policies and culture. With respect to the policy-related country context, it has been found that in countries where formal childcare coverage is minimal, such as Mediterranean countries and Poland, the family bears the main care responsibilities (Saraceno/Keck 2010). There, grandchild care provision is usually on a daily basis. Bordone and colleagues (2017) identified other two context-specific models of grandchild care in Europe. In Nordic countries and France, where public childcare services and parental leave are generous, grandparents take on a secondary role in childcare, helping when needed. An intermediate model is represented by most of the Western European countries and the Czech Republic, characterised by a lower offer of childcare services or parental leave than in Nordic countries, and by grandparents engaging in grandchild care with a lower frequency than in the first model but higher than in the second, i.e. usually on a weekly basis.

With respect to culture, other studies have focused on family norms. For example, using data from the European Social Survey, Jappens and Van Bavel (2012) showed that mothers in contexts characterised by more conservative family norms tend to rely on grandparents as the main source of childcare rather than on formal services.

Despite these studies on contextual effects on grandchild care use (from the parents' perspective) or provision (from the grandparents' one), there is a scarcity of studies analysing the moderating role of the country context in the relationship between provision of grandchild care and health or wellbeing of grandparents. In particular, to the best of our knowledge, no previous study has analysed whether the effect of grandchild care on health is moderated by country policies. However, Neuberger and Haberkern (2014) argued that the role of grandparents as providers of grandchild care may or may not be socially expected, depending on the context. They use the concept of structural ambivalence as the contradiction between behaviour and cultural norms, to suggest that in countries in which grandparents are normatively expected to provide grandchild care, not looking after grandchildren may favour negative feelings and therefore, in the case of our paper, contribute to grandparents' depressive symptoms. Conversely, in countries with low social expectations towards grandparenting, grandparents who provide grandchild care may answer a need in face of a particular situation and, in turn, experience more depressive symptoms.

Yet, structural and cultural factors may also vary within countries across the different regions (see e.g., Jappens/Van Bavel 2012 on family norms). Furthermore, the role of the context in moderating the effect of grandparenthood per se has also not been studied so far. Therefore, we take an exploratory approach in assessing whether the effects of grand- 
parenthood and of grandchild care on depression vary across countries but we refrain from formulating specific hypotheses in this respect.

\section{The gendered dimensions of grandparenthood}

The literature has largely shown a different engagement in the grandparental role between men and women. In particular, grandmothers on average provide more grandchild care than grandfathers. Although little has been done to explain such a gender gap (an exception is the work by Leopold and Skopek 2014), as highlighted by Arpino et al. (2018), it is more and more relevant to shed light on the grandparent-related gender gap in view of the increasing grandmothers' participation in the workforce that will make women more likely than men to experience competing roles in later life.

Economic theories of family labour, stressing the importance of time availability and specialization of tasks into market and non-market work, would suggest a convergence of grandfathers' and grandmothers' contributions to childcare in later life (after retirement) and little cross-national variation in the gender gap. Empirical evidence on the persistent higher engagement of grandmothers in grandchild care, however, tends to support sociological theories suggesting that gender roles go beyond the rational allocation of tasks. The socialisation/ideology hypothesis first (Coverman 1985) and the doing gender hypothesis later (West/Zimmerman 1987) posit that gender-related ideologies, internalised through socialisation and routinized within the institution of marriage, are at the base of the gendered division of labour.

The gendered division of the grandparenthood role is therefore likely to derive from the gendered tasks, responsibilities, and expectations traditionally associated with grandparenthood (Kaufman/Elder 2003; Stelle et al. 2010; Winefield/Air 2010), with some differences across Europe along the well-known North-South geographical divide of family-state division in caring responsibilities and corresponding to the societal framing of gender roles.

In turn, different effects of grandparenthood might be expected for grandmothers' and for grandfathers' health. For women, but not for men, grandparenthood may be perceived as prescriptive (Reitzes/Mutran 2004). Moreover, the increase of contact with adult children in the presence of grandchildren (e.g., Bordone 2009) is usually a reinforcement of the mother-daughter relationship and might also work as a mechanism of reduction of depressive symptoms especially for grandmothers, who traditionally hold the responsibilities as kin keepers. Indeed, Winefield and Air (2010) suggested that grandmothers, and in particular those belonging to older generations, view their grandparental role as an extension of their maternal role. We might therefore expect that becoming a grandmother, but not a grandfather, might positively affect mental health.

Although no striking differences by gender were found in the association between grandparenthood per se and life satisfaction, Arpino et al. (2018) noted a gender discrepancy with grandmothers often more satisfied when they provide grandchild care. Most of the empirical evidence on the gendered effects of grandparenthood on health has only considered grandchild care, showing for example better self-reported health and fewer functional limitations only among grandmothers in the USA (Hughes et al. 2007). Similarly, Grundy et al. (2012) found that Chilean grandmothers, but not grandfathers, who provided grandchild 
care had a lower risk of depression. However, other studies did not find substantial differences by gender (e.g. Arpino/Bordone (2014) on cognitive functioning).

Following Price et al.'s (2015) argument on wellbeing, we maintain that gender-specific marital and work lifecourse characteristics as well as gender differences in life expectancy (i.e., women generally live longer than men), socio-economic status (i.e., men have better financial resources than women), and socialization levels (i.e., men have more social exposure than women) are also likely to contribute to the gender gap in the association between grandchild care and depression, explaining the mixed results. We therefore stratify the analyses by gender and explore possible gender differences in such an association.

\section{Data and methods}

\section{Data}

We use panel data modelling on data from the Survey of Health, Ageing and Retirement in Europe (SHARE), which is a cross-national panel survey collecting micro-data on health, socio-economic status, and social and family networks of the non-institutionalised population aged 50 and older in Europe (Börsch-Supan et al. 2013; Börsch-Supan 2017a; Börsch-Supan 2017b; Börsch-Supan 2017c; Börsch-Supan 2017d). We pooled data from all regular waves of SHARE (waves 1, 2, 4, 5, and 6). Wave 3 (SHARELIFE) only collected retrospective information. We considered Israel and 17 European countries that participated in at least two waves of SHARE (Austria, Belgium, Czech Republic, Denmark, Estonia, France, Germany, Greece, Italy, Luxemburg, the Netherlands, Poland, Portugal, Slovenia, Spain, Sweden, and Switzerland).

We selected respondents aged 50-84 years old at the time of interview. The number of observations and relevant transitions outside this age range was extremely limited. We only considered respondents with at least one child. In this way, we avoid selection effects for grandchildless people (i.e., grandchildless respondents in our sample do not have grandchildren as a consequence of their children's behaviour and not of their own, as it would be for childless respondents). The overall working sample is composed of 35,442 women and 28,256 men (giving a total of 100,275 and 78,837 observations, respectively). The sample sizes for different analyses on the explanatory variables differ from these figures because of the different sample selection criterion described below and are detailed in Table 2. For example, for the transition to grandparenthood, where we selected only individuals who enter the sample being grandchildless, the sample sizes count 10,488 women and 10,060 men (16,262 and 15,609 observations, respectively). 
Table 1: Descriptive statistics on all variables on the full sample (mean or percentage, standard deviation - sd-, minimum and maximum)

\begin{tabular}{|c|c|c|c|c|c|c|c|c|}
\hline \multirow{2}{*}{ Variables } & \multicolumn{4}{|c|}{ Women } & \multicolumn{4}{|c|}{ Men } \\
\hline & mean & sd & $\min$ & $\max$ & mean & sd & $\min$ & $\max$ \\
\hline \multicolumn{9}{|l|}{ Outocome } \\
\hline Depressive symptoms (Euro-D) & 2.73 & 2.33 & 0 & 12 & 1.87 & 1.96 & 0 & 12 \\
\hline $\begin{array}{l}\text { Explanatory: } \\
\text { Grandparent (\%) } \\
\text { Additional grandchildren (\%) }\end{array}$ & $\begin{array}{l}25.00 \\
28.55\end{array}$ & & & & & $\begin{array}{l}24.18 \\
30.96\end{array}$ & & \\
\hline $\begin{array}{l}\text { Grandchild care (\%) } \\
\text { No care (ref.) } \\
\text { Not intensive care } \\
\text { Intensive care }\end{array}$ & $\begin{array}{l}48.09 \\
22.89 \\
29.02\end{array}$ & & & & & $\begin{array}{l}51.42 \\
24.34 \\
24.23\end{array}$ & & \\
\hline $\begin{array}{l}\text { Controls: } \\
\text { Age } \\
\text { Income rank }\end{array}$ & $\begin{array}{r}65.55 \\
0.48\end{array}$ & $\begin{array}{l}8.73 \\
0.29\end{array}$ & $\begin{array}{c}50 \\
0\end{array}$ & $\begin{array}{c}84 \\
1\end{array}$ & $\begin{array}{r}66.05 \\
0.55\end{array}$ & $\begin{array}{l}8.47 \\
0.28\end{array}$ & $\begin{array}{c}50 \\
0\end{array}$ & $\begin{array}{c}84 \\
1\end{array}$ \\
\hline $\begin{array}{l}\text { Partnership status (\%) } \\
\text { Living with partner (ref.) } \\
\text { Never married } \\
\text { Divorced } \\
\text { Widowed }\end{array}$ & $\begin{array}{r}69.31 \\
2.05 \\
9.83 \\
18.81\end{array}$ & & & & $\begin{array}{r}86.14 \\
1.66 \\
6.92 \\
5.28\end{array}$ & $\begin{array}{l}0.35 \\
0.13 \\
0.25 \\
0.22\end{array}$ & & \\
\hline $\begin{array}{l}\text { Working status (\%) } \\
\text { Retired (ref.) } \\
\text { Working } \\
\text { Other }\end{array}$ & $\begin{array}{l}50.54 \\
24.49 \\
24.98\end{array}$ & & & & $\begin{array}{r}61.93 \\
30.42 \\
7.65\end{array}$ & $\begin{array}{l}0.49 \\
0.46 \\
0.27\end{array}$ & & \\
\hline $\begin{array}{l}\text { Diagnosed conditions (\%) } \\
\text { GALI }^{1}(\%)\end{array}$ & $\begin{array}{l}51.98 \\
46.48\end{array}$ & & & & $\begin{array}{l}48.90 \\
41.29\end{array}$ & $\begin{array}{l}0.50 \\
0.49\end{array}$ & & \\
\hline Number of grandchildren & 3.08 & 3.15 & 0 & 20 & 2.75 & 3.00 & 0 & 20 \\
\hline $\begin{array}{l}\mathrm{N} \text { individuals } \\
\mathrm{N} \text { individuals } \mathrm{x} \text { waves }\end{array}$ & $\begin{array}{c}35,442 \\
100,275 \\
\end{array}$ & & & & $\begin{array}{l}28,256 \\
78,837 \\
\end{array}$ & & & \\
\hline
\end{tabular}

Note: For numerical variables, we report mean, standard deviation (sd), minimum, and maximum. For categorical variables, we report the percentage (\%) (in the column "mean") for each category and we specify the reference (ref.) category used in the regression models. Summary statistics are calculated on the total initial sample with the exception of explanatory variables that are calculated on the relevant sample instead. The sample sizes for the explanatory variables are reported in Table 2. 1. GALI = Global Activity Limitation Indicator.

Our dependent variable is the number of depressive symptoms, measured using the EURO-D scale, which is composed of 12 items, each measuring the presence of a specific depressive symptom. We used this variable as cardinal, ranging from 0 to 12 , as done by e.g., Arpino and Solé-Auró (2019). We also carried out the analyses by dichotomizing the EURO-D scale in a way that considered the presence of depression with scores higher than 4 (Crimmins et al. 2011; Prince et al. 1999) and results (available on request) were qualitatively similar to those presented here. 
Table 2: Descriptive statistics on some transitions observed for the explanatory variables

\begin{tabular}{|c|c|c|c|c|}
\hline \multirow{2}{*}{ Transitions between two waves } & \multicolumn{2}{|c|}{ Women } & \multicolumn{2}{|c|}{ Men } \\
\hline & $\%$ & $\mathbf{N}$ & $\%$ & $\mathbf{N}$ \\
\hline Became a grandparent & 23,8 & 2,496 & 23,1 & 2,324 \\
\hline $\mathrm{N}$ individuals & \multicolumn{2}{|c|}{10,488} & \multicolumn{2}{|c|}{10,060} \\
\hline $\mathrm{N}$ individuals $\mathrm{x}$ waves & \multicolumn{2}{|c|}{16,262} & \multicolumn{2}{|c|}{15,609} \\
\hline Had additional grandchildren & 82,5 & 20,111 & 85,2 & 15,074 \\
\hline $\mathrm{N}$ individuals & \multicolumn{2}{|c|}{24,378} & \multicolumn{2}{|c|}{17,693} \\
\hline $\mathrm{N}$ individuals $\mathrm{x}$ waves & \multicolumn{2}{|c|}{37,994} & \multicolumn{2}{|c|}{28,297} \\
\hline \multicolumn{5}{|l|}{ Grandchild care } \\
\hline Started doing not intensive care & 10,8 & 1,470 & 10,5 & 1026,0 \\
\hline Started doing intensive care & 8,7 & 1,180 & 8,9 & 834,0 \\
\hline $\mathrm{N}$ individuals & \multicolumn{2}{|c|}{22,077} & \multicolumn{2}{|c|}{14,941} \\
\hline $\mathrm{N}$ individuals $\mathrm{x}$ waves & \multicolumn{2}{|c|}{53,474} & \multicolumn{2}{|c|}{32.924} \\
\hline
\end{tabular}

Note: Became a grandparent: percentage and number of grandchildless individuals who became a grandparent over the observed period. Had an additional grandchild: percentage and number of grandparents that increased the number of grandchildren over the observed period. Grandchild care: percentage and number of grandparents that were not doing grandchild care at a given time point and started doing it either not intensively or intensively over the observed period. Other transitions are possible (e.g., from not intensive to intensive care) and data are available upon request.

\section{Methodological approach}

We use linear fixed-effects models to estimate the effect of various dimensions of grandparenthood on depressive symptoms. The key advantage of fixed-effects models over standard OLS regressions or random-effects models is that with fixed-effects we are able to eliminate all time-invariant factors that may confound the relationship of interest (e.g., personality traits, values, etc.). Fixed-effects models focus on within-individual variation in both the dependent and all independent variables. Therefore, the estimated effect can be interpreted as the effect of a change in the independent variable on a change in the dependent variable.

First, we focus on estimating the effect of the transition to grandparenthood (Model 1). For this analysis we keep only the subsample of individuals who are grandchildless at baseline, that is in the wave at which they first enter the survey. Our explanatory variable "grandparenthood" is a dummy variable indicating whether the respondent is a grandparent $(=1)$ or not $(=0)$. The fixed-effects estimate of the coefficient of this variable informs us about the effect of the transition to grandparenthood on the change in depressive symptoms. It is possible that more than one grandchild was born between two interviews. Therefore, as a robustness check, we dropped these cases (and subsequent observations) to be able to estimate the pure effect of becoming a grandparent rather than of an increase in the number of grandchildren.

Second, we estimate the effect of having an additional grandchild (Model 2). In this case, we select only individuals who were already grandparents at baseline. In this analysis, our explanatory variable "additional grandchildren" takes value 1 if there was an increase in the number of grandchildren over the observation period and 0 otherwise. 
Again, because it is possible that more than 1 grandchild was born between two waves, a robustness check was carried out on the subsample without individuals for which the increase in the number of grandchildren between two waves was higher than 1.

Third, we estimate the effect of grandchild care provision (Model 3). As for Model 2, we select individuals who entered the survey as grandparents. Drawing on the respondents' answers to the questions on provision of grandchild care (yes or no) and its frequency (almost daily, almost every week, almost every month, less often), we distinguish between engagement in intensive grandchild care (at least on a weekly basis), engagement in not-intensive grandchild care (less often than weekly), and no provision of grandchild care (reference category). Because it is possible that the transition from no care to provision of grandchild care is due to the birth of a(n additional) grandchild during the observation period, this model controls for the number of grandchildren in order to disentangle the effects of increasing the number of grandchildren and of providing grandchild care. Nonetheless, a robustness check keeps only grandparents for whom the number of grandchildren did not change over the observation period to avoid mixing these two effects.

In order to explore whether the effects of the grandparenthood-related variables change by country, we estimate a second set of models adding the interactions between the country dummies and the explanatory variables. In these models we could not consider Luxembourg and Portugal because of their very small sample sizes. Therefore, these models are based on 16 countries.

All multivariate analyses control for a set of variables that previous studies have found to be associated with older people's health and/or our explanatory variables of interest (e.g., Bordone/Arpino 2016; Di Gessa et al. 2016). Socio-demographic control variables include: age and its square; total net household income (a relative measure obtained transforming the information on net household income in ranks occupied within the country); marital status (living with partner (married or not) - reference -, never married, divorced, widowed); employment status (working, retired - reference -, other). We also control for two measures of health. First, we consider information on diagnosed conditions reported in response to the question "Has a doctor ever told you that you had any of the following conditions: Hypertension, diabetes, cancer, lung disease, heart disease, stroke and arthritis?" Our analyses include a dummy variable indicating whether the respondent reported at least one of these conditions. Second, we include a binary variable measuring global activity limitations (GALI), that takes value 1 for respondents who declared to be "limited, but not severely" or "severely limited" because of health problems in the activities people usually do (= 0 for respondents reporting not to be limited). In Model 3, where we estimate the effect of grandchild care provision, we also control for number of grandchildren. Given that fixed-effects models exploit only within-individual variations, we do not adjust for education, number of children, type of area of residence, and other variables that are (almost perfectly) time-invariant in our sample. These variables would be dropped from fixed-effects models. All analyses are run separately by gender. 


\section{Results}

\section{Descriptives}

Table 1 shows descriptive statistics on the full sample by gender. These, in line with existing knowledge, confirm that, on average, women report a higher number of depressive symptoms (2.73) than men (1.87). Women also report a higher number of diagnosed conditions and are more likely to report activity limitations than men. The percentage of widows is higher than that of widowers.

The summary statistics of the explanatory variables are calculated on the relevant sample, as selected for each analysis. For these variables we also report descriptive statistics on transitions occurring during the observation period. These transitions are the key source of variability used in the fixed-effects models. Table 2 shows that among respondents joining our sample as grandchildless, $23.8 \%$ of women and $23.1 \%$ of men experienced the transition to grandparenthood over the observation period. Among those who, instead, entered the sample already as grandparents, $82.5 \%$ of women and $85.2 \%$ of men faced an increase in their grandchildren's number. With respect to the provision of grandchild care, we calculated the percentage of grandparents that started providing grandchild care. Among both grandmothers and grandfathers who at a given point in time where not doing grandchild care, about $11 \%$ faced the transition to not intensive grandchild care and $9 \%$ to intensive caregiving over the observation period.

\section{Fixed-effects models estimates}

Table 3 presents the estimates for the models described above, that differ in the explanatory variable and sample of interest. These models are run on the pooled sample of countries, separately for women and men. Results from Model 1 show that women who become grandmothers benefit from a significant reduction in depressive symptoms. The results are similar for men, but the coefficient is much smaller and not statistically significant. As mentioned above, the effect estimated in Model 1 might not be, strictly speaking, the effect of having the first grandchild as more grandchildren could be born between two interviews. As a robustness check, Model A1 in Table A1 in the appendix reports the results from the same model estimated on the sample where those individuals who became grandparents to more than one grandchild during the observation period are excluded. Coefficients and standard errors remained virtually unchanged.

Model 2 in Table 3 reports the estimated effect of an increase in the number of grandchildren on depression for those individuals who entered the survey already as grandparents. In this case, the effect is not statistically significant for gender. The robustness check in Table A1, excluding individuals who experienced the birth of more grandchildren between two waves, gave the same results (Model A2).

Model 3 in Table 3 is run, as Model 2, on the subsample of individuals who were grandparents at the baseline wave, but here we also exclude missing observations on the grandchild care variable. The effects of intensive and not intensive grandchild care are reported in reference to no care. The estimated coefficients are very small and not statisti- 
cally significant for both women and men, indicating that changes in grandchild care provision do not influence changes in depression symptoms. The results are very similar to those of Model A3 in Table A1, where only grandparents for whom the number of grandchildren did not change over the observation period were retained (i.e., where we aimed at excluding an effect due to a change in the number of grandchildren).

Table 3: Fixed-effects models for the effect of becoming a grandparent (Model 1), having additional grandchildren (Model 2), and providing grandchild care (Model 3) on depressive symptoms, by gender

\begin{tabular}{|c|c|c|c|c|c|c|}
\hline \multirow{2}{*}{ Independent variables } & \multicolumn{2}{|c|}{ Model 1} & \multicolumn{2}{|c|}{ Model 2} & \multicolumn{2}{|c|}{ Model 3} \\
\hline & Women & Men & Women & Men & Women & Men \\
\hline Becoming a grandparent & $\begin{array}{c}-0.15^{\star \star} \\
(0.07)\end{array}$ & $\begin{array}{l}-0.03 \\
(0.06)\end{array}$ & & & & \\
\hline Additional grandchildren & & & $\begin{array}{l}-0.03 \\
(0.03)\end{array}$ & $\begin{array}{l}-0.04 \\
(0.03)\end{array}$ & & \\
\hline \multicolumn{7}{|c|}{ Grandchild care (Ref.: No care) } \\
\hline Not intensive care & & & & & $\begin{array}{c}0.04 \\
(0.03)\end{array}$ & $\begin{array}{c}0.04 \\
(0.03)\end{array}$ \\
\hline Intensive care & & & & & $\begin{array}{c}0.02 \\
(0.03)\end{array}$ & $\begin{array}{c}0.01 \\
(0.04)\end{array}$ \\
\hline Age & $\begin{array}{l}-0.13 \\
(0.08)\end{array}$ & $\begin{array}{l}-0.30^{* * *} \\
(0.07)\end{array}$ & $\begin{array}{l}-0.22^{* * *} \\
(0.04)\end{array}$ & $\begin{array}{l}-0.26^{* * *} \\
(0.05)\end{array}$ & $\begin{array}{l}-0.22^{* * *} \\
(0.03)\end{array}$ & $\begin{array}{l}-0.22^{* * *} \\
(0.04)\end{array}$ \\
\hline Age squared & $\begin{array}{c}0.00^{*} \\
(0.00)\end{array}$ & $\begin{array}{l}0.00^{* * *} \\
(0.00)\end{array}$ & $\begin{array}{l}0.00^{* * *} \\
(0.00)\end{array}$ & $\begin{array}{l}0.00^{* * *} \\
(0.00)\end{array}$ & $\begin{array}{l}0.00^{* * *} \\
(0.00)\end{array}$ & $\begin{array}{l}0.00^{\star * *} \\
(0.00)\end{array}$ \\
\hline Income rank & $\begin{array}{c}0.02 \\
(0.10)\end{array}$ & $\begin{array}{l}-0.07 \\
(0.09)\end{array}$ & $\begin{array}{l}-0.07 \\
(0.07)\end{array}$ & $\begin{array}{l}-0.01 \\
(0.07)\end{array}$ & $\begin{array}{l}-0.04 \\
(0.05)\end{array}$ & $\begin{array}{c}0.02 \\
(0.05)\end{array}$ \\
\hline \multicolumn{7}{|c|}{ Marital status (Ref.: Living with partner) } \\
\hline Never married & $\begin{array}{c}0.03 \\
(0.69)\end{array}$ & $\begin{array}{c}0.27 \\
(0.52)\end{array}$ & $\begin{array}{c}0.02 \\
(0.48)\end{array}$ & $\begin{array}{l}-0.52 \\
(0.38)\end{array}$ & $\begin{array}{c}0.70^{*} \\
(0.41)\end{array}$ & $\begin{array}{l}-0.46 \\
(0.43)\end{array}$ \\
\hline Divorced & $\begin{array}{c}0.11 \\
(0.32)\end{array}$ & $\begin{array}{r}0.48^{*} \\
(0.26)\end{array}$ & $\begin{array}{c}0.20 \\
(0.23)\end{array}$ & $\begin{array}{l}-0.22 \\
(0.23)\end{array}$ & $\begin{array}{l}0.36^{* *} \\
(0.17)\end{array}$ & $\begin{array}{l}-0.18 \\
(0.19)\end{array}$ \\
\hline Widowed & $\begin{array}{l}0.76^{\star \star \star} \\
(0.20)\end{array}$ & $\begin{array}{l}0.66^{* * *} \\
(0.25)\end{array}$ & $\begin{array}{l}0.74^{* \star *} \\
(0.10)\end{array}$ & $\begin{array}{l}0.88^{* * *} \\
(0.13)\end{array}$ & $\begin{array}{l}0.65^{* * *} \\
(0.06)\end{array}$ & $\begin{array}{l}0.79^{* * *} \\
(0.09)\end{array}$ \\
\hline \multicolumn{7}{|c|}{ Working status (Ref.: Retired) } \\
\hline Working & $\begin{array}{l}-0.10 \\
(0.09)\end{array}$ & $\begin{array}{c}0.13^{*} \\
(0.07)\end{array}$ & $\begin{array}{c}0.00 \\
(0.07)\end{array}$ & $\begin{array}{c}0.02 \\
(0.06)\end{array}$ & $\begin{array}{l}-0.04 \\
(0.05)\end{array}$ & $\begin{array}{c}0.02 \\
(0.05)\end{array}$ \\
\hline Other & $\begin{array}{c}0.04 \\
(0.09)\end{array}$ & $\begin{array}{l}0.32^{* * *} \\
(0.10)\end{array}$ & $\begin{array}{l}0.19^{* * *} \\
(0.06)\end{array}$ & $\begin{array}{l}0.20^{* * *} \\
(0.07)\end{array}$ & $\begin{array}{l}0.11^{\text {*** }} \\
(0.04)\end{array}$ & $\begin{array}{l}0.18^{* * *} \\
(0.06)\end{array}$ \\
\hline Diagnosed conditions & $\begin{array}{l}0.20^{* * *} \\
(0.06)\end{array}$ & $\begin{array}{l}0.24^{* * *} \\
(0.05)\end{array}$ & $\begin{array}{l}0.38^{* * *} \\
(0.04)\end{array}$ & $\begin{array}{l}0.26^{* * *} \\
(0.04)\end{array}$ & $\begin{array}{l}0.27^{* * *} \\
(0.03)\end{array}$ & $\begin{array}{l}0.16^{* * *} \\
(0.03)\end{array}$ \\
\hline $\mathrm{GALI}^{1}$ & $\begin{array}{l}0.57^{* \star *} \\
(0.06)\end{array}$ & $\begin{array}{l}0.39^{* * *} \\
(0.05)\end{array}$ & $\begin{array}{l}0.50^{* \star *} \\
(0.04)\end{array}$ & $\begin{array}{l}0.45^{\star * *} \\
(0.04)\end{array}$ & $\begin{array}{l}0.41^{* * *} \\
(0.03)\end{array}$ & $\begin{array}{l}0.45^{\star * *} \\
(0.03)\end{array}$ \\
\hline N. grandchildren & & & & & $\begin{array}{c}0.01 \\
(0.01)\end{array}$ & $\begin{array}{l}-0.00 \\
(0.01)\end{array}$ \\
\hline Constant & $\begin{array}{l}5.95^{* *} \\
(2.48)\end{array}$ & $\begin{array}{l}9.74^{\star \star *} \\
(2.12)\end{array}$ & $\begin{array}{c}9.29^{* * *} \\
(1.45)\end{array}$ & $\begin{array}{l}9.31^{* * *} \\
(1.62)\end{array}$ & $\begin{array}{l}9.52^{* * *} \\
(0.98)\end{array}$ & $\begin{array}{l}8.39^{* * *} \\
(1.23)\end{array}$ \\
\hline $\mathrm{N}$ individuals & 10,488 & 10,060 & 24,378 & 17,693 & 22,077 & 14,941 \\
\hline $\mathrm{N}$ individuals $\mathrm{x}$ waves & 16,262 & 15,609 & 37,994 & 28,297 & 53,474 & 32,924 \\
\hline
\end{tabular}

Note: Estimated coefficients and standard errors (in parentheses) are reported. 1. GALI = Global Activity Limitation Indicator. Significance level: $* * * \mathrm{p}<0.01 ; * \mathrm{p}<0.05 ; * \mathrm{p}<0.1$.

The previous findings seem to indicate null effects of grandparenthood-related variables on depression for both genders. The only exception is found for the transition to grandparenthood for women that is significantly associated with a reduction in depressive 
symptoms. The magnitude of the effect in this case $(-0.15)$ is also not negligible, considering the mean and standard deviation of the outcome variable (Table 1) and also the effect of other variables such as diagnosed conditions $(-0.20)$. We have also re-estimated the previous models (including the robustness checks) pooling the samples of women and men and adding interactions with gender. These models (available on request) confirmed the statistically significant difference in the effect of the transition to grandparenthood for women and men $(p<0.01)$ and the absence of statistically significant differences by gender in the effect of number of grandchildren and grandchild care (null for both genders).

It is however important to note that the previous findings are overall average findings obtained on the whole sample of countries and they can mask important country variation that we explore in the following section.

\section{Cross-country variability}

Country variation in the effect of grandparenthood was examined by re-running previous analyses with the addition of interactions between country dummies and the explanatory variables. As noticed above, in this set of analyses we had to drop Luxembourg and Portugal because of small sample sizes. As the number of countries and of the corresponding interactions (16) is too large to be interpreted directly in the regression results, we ease their interpretation by plotting the relevant marginal effect for each model by gender and country. That is, we plot the predicted change in depressive symptoms that corresponds to a change in the explanatory variables.

The marginal effects shown in the top panels of Figure 1 (Figure 1a) refer to the transition to grandparenthood (Model 1); while those in the bottom panels (Figure 1b) refer to the transition to additional grandchildren (Model 2). Countries are displayed in ascending order of the percentage of intensive grandchild care (descriptives on this variable are reported in Table A.2 in the appendix). As the variation in the explanatory variables in the country samples is not too large, we interpret the results that are statistically significant at $5 \%$ (i.e., $\mathrm{p}<0.05$ ), but we also mention those significant at $10 \%$ (i.e., $\mathrm{p}<0.10$ ).

Figure 1a shows that the effect of the transition to grandmotherhood found in Model 1 of Table 3 on the pooled sample does not apply to all countries. The estimated marginal effect is not statistically significant in most countries. The marginal effect shows statistically significantly lower depression symptoms associated with grandmotherhood in Spain and Israel (at the 5\%) as well as in Sweden and Denmark (at 10\%). Thus, women who became grandmothers over the observation period in these countries experienced, on average, a reduction in depressive symptoms. The contrary holds for Italy, which is the only country where the transition to grandmotherhood increased, on average, women's depressive symptoms. No marginal effects are statistically significant at $5 \%$ level in the analysis of grandfatherhood. Yet, consistently with what found for women, also Italian men who made the transition to grandparenthood experienced, on average, a statistically significant increase in depressive symptoms (at 10\%). 
Figure 1: $\quad$ Marginal effects (ME) from fixed-effects models for the effect of a) becoming a grandparent and $b$ ) having additional grandchildren on depressive symptoms, by gender and country.
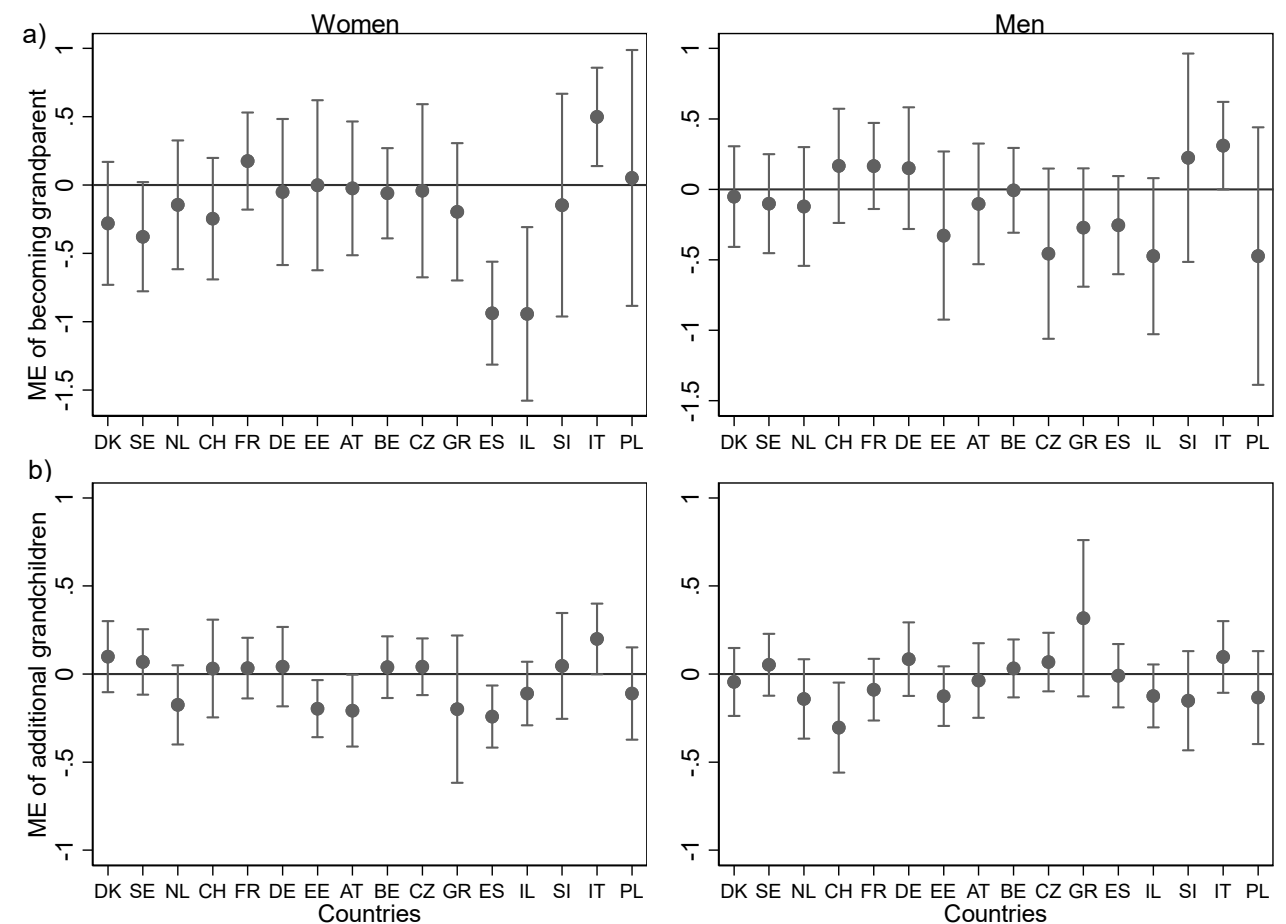

Note: Countries are in ascending order by the proportion of grandparents involved in intensive grandchild care. Marginal effects and 95\% confidence intervals are obtained from models similar to Models 1 and 2 in Table 2 with the addition of interactions between the explanatory variables and the country dummies. All control variables are included as in Table 2.

Figure $1 \mathrm{~b}$ shows that the marginal effects of having additional grandchildren tend to be even smaller than those for the transition to grandparenthood, for all countries and both genders. Having additional grandchildren significantly reduces the symptoms of depression in Spain, Estonia (at 5\%) and Austria (at 10\%) for women and in Switzerland (at 5\%) for men. The only country where a statistically significant (at 10\%) effect points to an increase in depressive symptoms for an increase in number of grandchildren is again Italy, where grandmothers who experience the transition to additional grandchildren face increasing depressive symptoms. 
Figure 2: Marginal effects (ME) from fixed-effects models for the effect of a) providing not intensive or b) intensive grandchild care compared to not providing grandchild care on depressive symptoms, by gender and country.
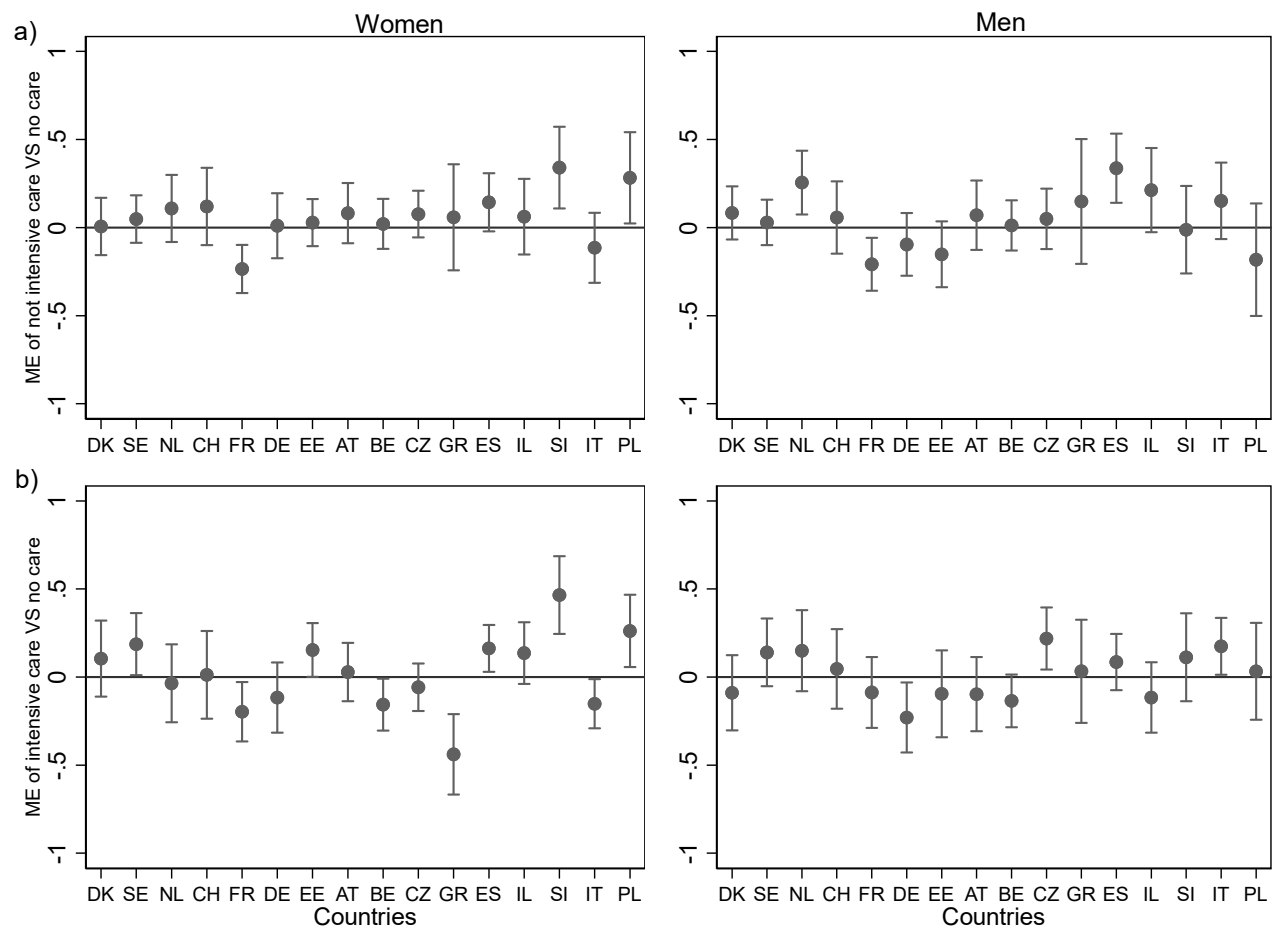

Note: Countries are in ascending order by the proportion of grandparents involved in intensive grandchild care. Marginal effects and 95\% confidence intervals are obtained from models similar to Model 3 in Table 2 with the addition of interactions between the explanatory variable and the country dummies. All control variables are included as in Table 2.

Figure 2 presents, by country, the effect on changes in depressive symptoms of provision of not intensive grandchild care (top panels, Figure 1a) and of intensive grandchild care (bottom panels, Figure 1b), compared to having grandchildren but not providing care to any of them (Model 3). While not intensive grandchild care is associated with a reduction in depressive symptoms for both women and men in France (at 5\%), it has an opposite effect in several other countries (for women, in Slovenia and Poland, both at 5\% and in Spain, at 10\%; for men, in the Netherlands, Spain, Israel, and Italy, at $10 \%$ in the two latter cases). The marginal effect of intensive grandchild care is the one that most frequently results in being statistically significant, especially for women. In several countries we found that increasing provision of grandchild care to intensive level increases depression among women (in Poland, Slovenia, Israel, Spain, Estonia, and Sweden). Yet, the opposite is true in Italy, Greece, Belgium, and France. Intensive provision of grandchild care on the side of grandfathers reduces their depression in Belgium and Germany and increases it in Italy and Czech Republic (all at 5\%). 


\section{Discussion}

In times of increasing longevity and decreasing fertility, research on how to maintain mental health in later life becomes central. This study focused on the increasing opportunity that demographic change has created for the grandparental role and, drawing on previous literature suggesting mixed results on its effects for grandparents, we investigated the impact of grandparenthood on older people's depressive symptoms. In doing so, we added to the literature in at least three ways: by accounting for the multidimensionality of the concept of grandparenthood, by exploring the contextual variation, and, from a methodological point of view, by using fixed-effects panel models that allowed us to study within-individual variation while accounting for observed and unobserved timeconstant variables. Furthermore, we considered possible gender differences.

The findings from our fixed-effects analyses showed that, in general, grandparenthood does not affect grandparents' depressive symptoms. This holds especially for its components of having additional grandchildren and provision of (intensive or not intensive) grandchild care. While this seems to contradict earlier literature from the USA, it is in line with recent European studies (e.g., Di Gessa et al. 2016). One explanation for this finding may refer to the methodological approach that we use, i.e., fixed-effects models. Indeed, Ates (2017) showed that a positive effect of grandchild care on self-rated health found using a random effects model, turned to be not statistically significant in fixed-effects models. This suggests that studies that did not focus on within-person variations, but rather on between-person variations, might have overestimated the effect of grandchild care. The fact that fixed-effects models show non-significant results may be due to the presence of some time-invariant unobserved factors, such as family values or personality traits that may be positively associated with both health and the likelihood of providing care.

There is an interesting gender difference in the effect of grandparenthood per se in which becoming a grandmother brings together a reduction in depressive symptoms. As mentioned above, this might be due to the gendered tasks, responsibilities, and expectations traditionally associated with grandparenthood (Kaufman/Elder 2003; Stelle et al. 2010; Winefield/Air 2010). However, it should be noted that such gender gap in the division of labour varies across Europe (Leopold/Skopek 2014). Indeed, once we explored the effects of grandparenthood per se on depressive symptoms in a cross-country comparative way, we found contrasting results. This holds also for the effect of having additional grandchildren, which, however, tends to be smaller than that of the transition to grandparenthood, most likely because becoming a grandparent is a much more salient transition in a person's life course than the birth of the second or third grandchild.

We did not find a clear grandparenthood-related country pattern of depression in later life. However, we identified important differences across countries and our results point to the importance of considering contextual influences on the consequences of grandparenthood. An interesting avenue for future studies is to examine how specific policy and cultural contextual factors at the country (but also at the regional) level may moderate the effect of grandparenthood and grandchild care.

In line with the findings of Arpino et al. (2018) of higher subjective wellbeing in Europe for grandparents in Scandinavian countries, we found lower depression symptoms 
associated with the transition to grandmotherhood in Sweden and Denmark. Yet, our study points to the need of further investigating and comparing different countries and childcare provision in future research with a higher degree of details to explain surprising findings. For example, our results on two (apparently) similar countries in terms of grandchild care provision as well as in welfare systems, such as Italy and Spain, showed opposite effects of the transition to grandparenthood of either first or higher orders. While becoming a grandmother and having additional grandchildren in Spain is associated with a decrease in depressive symptoms, becoming a grandparent to the first or to additional grandchildren in Italy tends to increase depressive symptoms.

Our findings about differences between Italy and Spain, two countries that are commonly considered as very similar to each other, call for deeper comparative analyses on these contexts. Using data from the European Values Study, Arpino and Tavares (2013) found substantial differences between Italy and Spain in a bunch of attitudinal items, with Spaniards reporting less often "traditional" attitudes than Italians. Our findings vis-à-vis Arpino and Tavares' (2013) results suggest that similarities and differences between countries that are usually grouped together in the same cluster would need to be further investigated.

The effects found for not intensive and intensive grandchild care hint to the need to collect information on whether the caregiving role of grandparents is wished and therefore a voluntary engagement or somehow imposed either by the needs of childcare not satisfied by scarce/expensive public services or by peculiar (negative) events experienced for example by the grandchild's parents. In fact, grandparents engaging in grandchild care face a decrease in depressive symptoms in France, where the welfare system is quite family oriented and intensive grandchild care provision is not much common. There, the ambivalence theory would suggest an increase of depression for grandparents engaging in grandchild care. Yet, we may think that doing grandchild care in a context where grandparents are one of the many available childcare options might be a matter of choice (of parents and grandparents). On the contrary, we find that grandmothers' engagement in grandchild care increases depression symptomatology in Eastern European countries, where public childcare is less available while female labour market participation tends to be relatively high (see also Bordone et al. 2017). This suggests that grandparental childcare as an answer to (unsatisfied) needs might have detrimental effects. These considerations further hint to the importance of accounting for both cultural and policy-related contextual influences when analysing the effect of caregiving on caregivers' health.

We recognise that there still is a need to add knowledge on how exactly context matters in moderating the effect of grandparenthood on grandparents' mental health, especially in respect to apparently contradictory results, but we believe that this study allowed us to go further in this direction.

We also acknowledge some limitations of our study. First, once looking at countryspecific analyses, the variation in the explanatory variables might be limited and this might also hide possible significant effects. Second, we should bear in mind the inability of fixedeffects analysis to account for reverse causality, i.e. the possibility that the estimated associations are biased because of changes in the outcome influencing changes in the independent variables. This issue may be particularly relevant for the estimated association between grandchild care and depression because grandparents who experience an increase of depressive symptoms may be less likely to (be asked to) look after their grandchildren. 
We can however gain from this research by considering it as the base for future studies. In particular, our results highlight that the heterogeneity across countries within Europe is a relevant factor in shaping the effects of becoming a grandparent, having additional grandchildren, and engaging in grandchild care on older people's mental health, partly depending on the context where grandparents are embedded, including norms, values, needs, and opportunities for older people as well as for their children and grandchildren. Unfortunately, often the country-specific samples of surveys on older people are not big enough to carry out country comparative analyses and researchers cope with this issue by clustering countries in macro regions similar in e.g., welfare provisions. Future studies might be able to explore specific country comparisons by relying on bigger and richer data. As mentioned by Hank and colleagues (2018) while reviewing what has been achieved so far and which lessons we can learn for the future of research on intergenerational relationships, additional struggles of this field of research relate to the need to ask more refined substantive questions about the subjective aspects of grandparenthood and of grandparent identity; but also to give grandparenthood and grandchild care adequate attention in the sample design of surveys on older populations in order to allow quantitative approaches to the study of specific (smaller) subpopulations, such as those facing transitions to grandparenthood or changing the intensity of grandchild care. Finally, other than a better understanding of the heterogeneity of grandparenthood/grandchild care effects across countries, more research should be also devoted to analyse the possible moderating role of individual characteristics such as education (Arpino et al. 2018).

Important steps forward in the study of grandparenthood and its effects were done in this work by exploring separately the effects of multiple dimensions of grandparenthood on older people's depressive symptoms and, methodologically, by using longitudinal methods of analyses that rely on within-person variation. This latter is important because it allowed us to rule out the influence of time-invariant unobserved factors.

The positive message that can be taken from our study is that in general there is no negative effect of grandparenthood and related activities on grandparents' depression and when a statistically significant effect was found (transition to grandparenthood for women) it actually implied a reduction in depressive symptoms. These results are important in the light of a growing number of older people involved in grandchild care activities. Overall, this involvement does not seem to negatively impact on grandparents' mental health. Given that other studies have found positive effects of grandchild care on other dimensions of health and healthy behaviours, our findings would reinforce the idea of considering grandchild care as an activity that may help older people to remain physically and cognitively engaged without being detrimental for their mental wellbeing.

\section{References}

Arpino, B. \& Bordone, V. (2014). Does grandparenting pay off? The effect of child care on grandparents' cognitive functioning. Journal of Marriage and Family, 76, 2, pp. 337-351. doi:10.1111/jomf.12096.

Arpino, B., Bordone, V. \& Balbo, N. (2018). Grandparenting, education and subjective well-being of older Europeans. European Journal of Ageing, 15, 3, pp. 251-263. doi:10.1007/s10433-018-0467-2. 
Arpino, B., \& Tavares, L. P. (2013). Fertility and values in Italy and Spain: A look at regional differences within the European context. Population Review, 52, 1, pp. 62-86. doi:10.1353/prv.2013.0004.

Arpino, B. \& Solé-Auró, A. (2019). Education inequalities in health among older European men and women: The role of active aging. Journal of Aging and Health, 31, 1, pp. 185-208. doi: $10.1177 / 0898264317726390$.

Ates, M. (2017). Does grandchild care influence grandparents' self-rated health? Evidence from a fixed effects approach. Social Science \& Medicine, 190, pp. 67-74. doi:10.1016/j.socscimed.2017.08.021.

Barak, B. \& Gould, S. (1985). Alternative age measures: A research agenda. In: Hirschman, E. C. \& Holbrook, M. B. (Eds.), NA - Advances in Consumer Research. Provo, UT: Association for Consumer Research, pp. 53-58.

Blazer, D. G. (2003). Depression in later life: review and commentary. The Journals of Gerontology: Series $A$, 58, 3, pp. M249-M265. doi:10.1093/gerona/58.3.M249.

Blustein, J., Chan, S. \& Guanais, F. C. (2004). Elevated depressive symptoms among caregiving grandparents. Health Services Research, 39, 6pt1, pp. 1671-1690. doi:10.1111/j.1475-6773.2004.00312.x.

Bordone, V. (2009). Contact and proximity of older people to their adult children: A comparison between Italy and Sweden. Population, Space and Place, 15, 4, pp. 359-380. doi:10.1002/psp.559

Bordone, V. \& Arpino, B. (2016). Do grandchildren influence how old you feel? Journal of Aging and Health, 28, 6, pp. 1055-1072. doi:10.1177/0898264315618920.

Bordone, V., Arpino, B. \& Aassve, A. (2017). Patterns of grandparental child care across Europe: the role of the policy context and working mothers' need. Ageing \& Society, 37, 4, pp. 845-873. doi:10.1017/S0144686X1600009X.

Börsch-Supan, A. (2017a). Survey of Health, Ageing and Retirement in Europe (SHARE) Wave 2. Release version: 6.0.0. SHARE-ERIC. Data set.

Börsch-Supan, A. (2017b). Survey of Health, Ageing and Retirement in Europe (SHARE) Wave 4. Release version: 6.0.0. SHARE-ERIC. Data set.

Börsch-Supan, A. (2017c). Survey of Health, Ageing and Retirement in Europe (SHARE) Wave 5. Release version: 6.0.0. SHARE-ERIC. Data set.

Börsch-Supan, A. (2017d). Survey of Health, Ageing and Retirement in Europe (SHARE) Wave 6. Release version: 6.0.0. SHARE-ERIC. Data set.

Börsch-Supan, A., Brandt, M., Hunkler, C., Kneip, T., Korbmacher, J., Malter, F., Schaan, B., Stuck, S. \& Zuber, S. (2013). Data resource profile: The Survey of Health, Ageing and Retirement in Europe (SHARE). International Journal of Epidemiology, 42, 4, pp. 992-1001. doi:10.1093/ije/dyt088.

Brunello, G., \& Rocco, L. (2019). Grandparents in the blues. The effect of childcare on grandparents' depression. Review of Economics of the Household, 17, 2, pp. 587-613. doi:10.1007/s11150-018-9432-2.

Christiansen, S. G. (2014). The association between grandparenthood and mortality. Social Science \& Medicine, 118, pp. 89-96. doi:10.1016/j.socscimed.2014.07.061

Chung, S. \& Park, A. (2018). The longitudinal effects of grandchild care on depressive symptoms and physical health of grandmothers in South Korea: a latent growth approach. Aging \& Mental Health, 22, 12, pp. 1556-1563. doi:10.1080/13607863.2017.1376312.

Coall, D. A. \& Hertwig, R. (2011). Grandparental investment: A relic of the past or a resource for the future? Current Directions in Psychological Science, 20, 2, pp. 93-98. doi:10.1177/0963721411403269.

Condon, J., Luszcz, M. \& McKee, I. (2018). The transition to grandparenthood: a prospective study of mental health implications. Aging \& Mental Health, 22, 3, pp. 336-343. doi:10.1080/13607863.2016.1248897.

Crimmins, E. M., Kim, J. K. \& Solé-Auró, A. (2011). Gender differences in health: results from SHARE, ELSA and HRS. The European Journal of Public Health, 21, 1, pp. 81-91. doi:10.1093/eurpub/ckq022. 
Dalgard, O. S., Bjork, S. \& Tambs, K. (1995). Social support, negative life events and mental health. The British Journal of Psychiatry, 166, 1, pp. 29-34. doi:10.1192/bjp.166.1.29.

Danielsbacka, M. \& Tanskanen, A. O. (2016). The association between grandparental investment and grandparents' happiness in Finland. Personal Relationships, 23, 4, pp. 787-800. doi:10.1111/pere.12160.

Di Gessa, G., Glaser, K. \& Tinker, A. (2016). The health impact of intensive and nonintensive grandchild care in Europe: New evidence from SHARE. The Journals of Gerontology: Series B, 71, 5, pp. 867-879. doi:10.1093/geronb/gbv055.

Ferrari, A. J., Charlson, F. J., Norman, R. E., Patten, S. B., Freedman, G., Murray, C. J. L., Vos, T. \& Whiteford, H. A. (2013). Burden of depressive disorders by country, sex, age, and year: findings from the global burden of disease study 2010. PLoS Medicine, 10, 11, pp. e1001547. doi:10.1371/journal.pmed.1001547.

Fujiwara, T. \& Lee, C. K. (2008). The impact of altruistic behaviours for children and grandchildren on major depression among parents and grandparents in the United States: A prospective study. Journal of Affective Disorders, 107, pp. 29-36. doi:/10.1016/j.jad.2007.08.016.

Fuller-Thomson, E. \& Minkler, M. (2001). American grandparents providing extensive child care to their grandchildren: Prevalence and profile. The Gerontologist, 41, 2, pp. 201-209. doi:10.1093/geront/41.2.201.

Gallagher D., Savva G., Kenny R. \& Lawlor B. A. (2012). What predicts persistent depression in older adults across Europe? Utility of clinical and neuropsychological predictors from the SHARE study. Journal of Affective Disorders, 147, 1, pp. 192-197. doi:10.1016/j.jad.2012.10.037.

Grinstead, L. N., Leder, S., Jensen, S. \& Bond, L. (2003). Review of research on the health of caregiving grandparents. Journal of Advanced Nursing, 44, 3, pp. 318-326. doi:10.1046/j.1365-2648.2003.02807.x.

Grundy, E. M., Albala, C., Allen, E., Dangour, A. D., Elbourne, D. \& Uauy, R. (2012). Grandparenting and psychosocial health among older Chileans: A longitudinal analysis. Aging \& Mental Health, 16, 8, pp. 1047-1057. doi:10.1080/13607863.2012.692766.

Hank, K. \& Buber, I. (2009). Grandparents caring for their grandchildren: Findings from the 2004 Survey of Health, Ageing, and Retirement in Europe. Journal of Family Issues, 30, 1, pp. 53-73. doi:10.1177/0192513X08322627.

Hank, K., Cavrini, G., Di Gessa, G. \& Tomassini, C. (2018). What do we know about grandparents? Insights from current quantitative data and identification of future data needs. European Journal of Ageing, 15, 3, pp. 225-235. doi:10.1007/s10433-018-0468-1.

Hayslip, B. \& Kaminski, P. L. (2005). Grandparents raising their grandchildren: A review of the literature and suggestions for practice. Gerontologist, 45, 2, pp. 262-269. doi:10.1093/geront/45.2.262.

Hughes, M. E., Waite, L. J., LaPierre, T. A. \& Luo, Y. (2007). All in the family: the impact of caring for grandchildren on grandparents' health. The Journals of Gerontology: Series B, 62, 2, pp. S108-119. doi:10.1093/geronb/62.2.s108.

Jappens, M., \& Van Bavel, J. (2012). Regional family norms and child care by grandparents in Europe. Demographic research, 27, 4, pp. 85-120. doi:10.4054/DemRes.2012.27.4.

Jendrek, M. P. (1993). Grandparents who parent their grandchildren - Effects on lifestyle. Journal of Marriage and the Family, 55, 3, pp. 609-621. doi:10.2307/353342.

Kaufman, G. \& Elder, G. H. (2003). Grandparenting and age identity. Journal of Aging Studies, 17, 3, pp. 269-282. doi:10.1016/S0890-4065(03)00030-6.

Kok, R., Avendano, M., Bago d'Uva, T. \& Mackenbach, J. (2012). Can reporting heterogeneity explain differences in depressive symptoms across Europe? Social Indicators Research, 105, 2, pp. 191-210. doi:10.1007/s11205-011-9877-7.

Ku, L.-J. E., Stearns, S. C., Houtven, V., H, C., Lee, S.-Y. D., Dilworth-Anderson, P. \& Konrad, T. R. (2013). Impact of caring for grandchildren on the health of grandparents in Taiwan. The Journals of Gerontology: Series B, 68, 6, pp. 1009-1021. doi:10.1093/geronb/gbt090.

Kuo, S. Y., Lin, K. M., Chen, C. Y., Chuang, Y. L., \& Chen, W. J. (2011). Depression trajectories and obesity among the elderly in Taiwan. Psychological medicine, 41, 8, pp. 1665-1676. doi:10.1017/S0033291710002473. 
Leopold, T. \& Skopek, J. (2014). Gender and the division of labor in older couples: How European grandparents share market work and childcare. Social Forces, 93, 1, pp. 63-91. doi: $10.1093 / \mathrm{sf} / \mathrm{sou} 061$.

Leopold, T. \& Skopek, J. (2015). The demography of grandparenthood: An international profile. Social Forces, 94, 2, pp. 801-832. doi: 10.1093/sf/sov066.

Margolis, R. (2016). The changing demography of grandparenthood. Journal of Marriage and Family, 78, 3, pp. 610-622. doi: 10.1111/jomf.12286.

McCabe, C. J., Thomas, K. J., Brazier, J. E. \& Coleman, P. (1996). Measuring the mental health status of a population: a comparison of the GHQ-12 and the SF-36 (MHI-5). The British Journal of Psychiatry, 169, 4, pp. 517-521.

Minkler, M. \& Fuller-Thomson, E. (1999). The health of grandparents raising grandchildren: results of a national study. American Journal of Public Health, 89, 9, pp. 1384-1389. doi: 10.2105/AJPH.89.9.1384.

Minkler, M., Fuller-Thomson, E., Miller, D. \& Driver, D. (1997). Depression in grandparents raising grandchildren: results of a national longitudinal study. Archives of Family Medicine, 6, 5, pp. 445452.

Moussavi, S., Chatterji, S., Verdes, E., Tandon, A., Patel, V., \& Ustun, B. (2007). Depression, chronic diseases, and decrements in health: results from the World Health Surveys. The Lancet, 370, 9590, 851-858. doi: 10.1016/S0140-6736(07)61415-9.

Musil, C. M., Jeanblanc, A. B., Burant, C. J., Zauszniewski, J. A. \& Warner, C. B. (2013). Longitudinal analysis of resourcefulness, family strain, and depressive symptoms in grandmother caregivers. Nursing Outlook, 61, 4, pp. 225-234.e2. doi: 10.1016/j.outlook.2013.04.009.

Musil, C., Warner, C., Zauszniewski, J., Wykle, M. \& Standing, T. (2009). Grandmother caregiving, family stress and strain, and depressive symptoms. Western Journal of Nursing Research, 31, 3, pp. 389-408. doi: 10.1177/0193945908328262.

Neuberger, F. S. \& Haberkern, K. (2014). Structured ambivalence in grandchild care and the quality of life among European grandparents. European Journal of Ageing, 11, 2, pp. 171-181. doi: 10.1007/s10433-013-0294-4.

Price, D., Glaser, K., Ginn, J. \& Nicholls, M. (2016). How important are state transfers for reducing poverty rates in later life? Ageing \& Society, 36, 9, pp.1794-1825. doi: 10.1017/S0144686X15000690.

Prince, M. J., Reischies, F., Beekman, A. T., Fuhrer, R., Jonker, C., Kivela, S. L., Lawlor, B. A., Lobo, A., Magnusson, H., Fichter, M., van Oyen, H., Roelands, M., Skoog, I., Turrina, C. \& Copeland, J. R. (1999). Development of the EURO-D scale - a European Union initiative to compare symptoms of depression in 14 European centres. The British Journal of Psychiatry: The Journal of Mental Science, 174 , pp. 330-338.

Reitzes, D. C. \& Mutran, E. J. (2004). Grandparenthood: Factors influencing frequency of grandparentgrandchildren contact and grandparent role satisfaction. The Journal of Gerontology, Series B: Psychological Sciences \& Social Sciences, 59, 1, pp. S9-S16. doi: 10.1093/geronb/59.1.S9.

Saraceno, C. \& Keck, W. (2010). Can we identify intergenerational policy regimes in Europe? European Societies, 12, 5, pp. 675-696. doi: 10.1080/14616696.2010.483006.

Silverstein, M., Giarrusso, R. \& Bengtson, V. L. (1998). Intergenerational solidarity and the grandparent role. In: Szinovacz, M. E. (ed), Handbook on grandparenthood. Westport, CT: Greenwood Press, pp. 144-158.

Stelle, C., Fruhauf, C. A., Orel, N. \& Landry-Meyer, L. (2010). Grandparenting in the 21 st century: issues of diversity in grandparent-grandchild relationships. Journal of Gerontological Social Work, 53, 8, pp. 682-701. doi: 10.1080/01634372.2010.516804.

Szinovacz, M. E., DeViney, S. \& Atkinson, M. P. (1999). Effects of surrogate parenting on grandparents' well-being. The Journals of Gerontology: Series B, 54, 6, pp. S376-S388. doi: 10.1093/geronb/54b.6.s376.

Ustün, T. B., Ayuso-Mateos, J. L., Chatterji, S., Mathers, C. \& Murray, J. L. (2004). Global burden of depressive disorders in the year 2000. British Journal of Psychiatry, 184, pp. 386-392. 
Waldrop, D. \& Weber, J. (2001). From grandparent to caregiver: The stress and satisfaction of raising grandchildren. Families in Society: The Journal of Contemporary Social Services, 82, 5, pp. 461-472. doi: 10.1606/1044-3894.177.

Whitley, D. M., Kelley, S. J. \& Lamis, D. A. (2016). Depression, social support, and mental health: A longitudinal mediation analysis in African American custodial grandmothers. The International Journal of Aging and Human Development, 82, 2-3, pp. 166-187. doi: 10.1177/0091415015626550.

WHO (2002). Active ageing: a policy framework. Geneva: WHO.

Winefield, H. \& Air, T. (2010). Grandparenting: diversity in grandparent experiences and needs for healthcare and support. International Journal of Evidence-Based Healthcare, 8, 4, pp. 277-283.

Zaidi, A., Gasior, K., Hofmarcher, M. M., Lelkes, O. et al. (2013). Active ageing index 2012: Concept, methodology and final results. Vienna, Austria: European Centre for Social Welfare Policy and Research.

Submitted: November 11, 2018

Accepted: June 18, 2019

Adresses of the authors:

Valeria Bordone (Corresponding author)

Department of Sociology

University of Vienna

Rooseveltplatz, 2

1090 Vienna

Austria

Email: valeria.bordone@univie.ac.at

Bruno Arpino

Department of Statistics

Computer Science, Applications

University of Florence

Viale Morgagni, 59

50134 Florence

Italy

Email: bruno.arpino@unifi.it 


\section{Appendix}

Table A1: Linear fixed-effects models for the effect of becoming a grandparent (Model A1), having an additional grandchild (Model A2), and providing grandchild care (Model A3) on depressive symptoms (different specifications or selections compared to models in Table 3 in the text)

\begin{tabular}{|c|c|c|c|c|c|c|}
\hline \multirow{2}{*}{ Independent variables } & \multicolumn{2}{|c|}{ Model A1 } & \multicolumn{2}{|c|}{ Model A2 } & \multicolumn{2}{|c|}{ Model A3 } \\
\hline & Women & Men & Women & Men & Women & Men \\
\hline Becoming a grandparent & $\begin{array}{l}-0.15^{\star *} \\
(0.08)\end{array}$ & $\begin{array}{l}-0.07 \\
(0.07)\end{array}$ & & & & \\
\hline Additional grandchild & & & $\begin{array}{l}-0.03 \\
(0.03)\end{array}$ & $\begin{array}{l}-0.04 \\
(0.03)\end{array}$ & & \\
\hline \multicolumn{7}{|c|}{ Grandchild care (Ref.: No care) } \\
\hline Not intensive care & & & & & $\begin{array}{c}0.04 \\
(0.04)\end{array}$ & $\begin{array}{c}0.05 \\
(0.04)\end{array}$ \\
\hline Intensive care & & & & & $\begin{array}{c}0.01 \\
(0.04)\end{array}$ & $\begin{array}{c}0.02 \\
(0.04)\end{array}$ \\
\hline Age & $\begin{array}{l}-0.09 \\
(0.08)\end{array}$ & $\begin{array}{l}-0.30^{* * *} \\
(0.07)\end{array}$ & $\begin{array}{l}-0.22^{* * *} \\
(0.04)\end{array}$ & $\begin{array}{l}-0.25^{\star * *} \\
(0.05)\end{array}$ & $\begin{array}{l}-0.20^{* * *} \\
(0.03)\end{array}$ & $\begin{array}{l}-0.21^{* * *} \\
(0.04)\end{array}$ \\
\hline Age squared & $\begin{array}{c}0.00 \\
(0.00)\end{array}$ & $\begin{array}{l}0.00^{* * *} \\
(0.00)\end{array}$ & $\begin{array}{l}0.00^{\star * *} \\
(0.00)\end{array}$ & $\begin{array}{l}0.00^{* * *} \\
(0.00)\end{array}$ & $\begin{array}{l}0.00^{\star * *} \\
(0.00)\end{array}$ & $\begin{array}{l}0.00^{* * *} \\
(0.00)\end{array}$ \\
\hline Income rank & $\begin{array}{l}-0.00 \\
(0.10)\end{array}$ & $\begin{array}{l}-0.09 \\
(0.09)\end{array}$ & $\begin{array}{l}-0.06 \\
(0.07)\end{array}$ & $\begin{array}{c}0.00 \\
(0.07)\end{array}$ & $\begin{array}{l}-0.00 \\
(0.05)\end{array}$ & $\begin{array}{c}0.00 \\
(0.06)\end{array}$ \\
\hline \multicolumn{7}{|c|}{ Marital status (Ref.: Living with partner) } \\
\hline Never married & $\begin{array}{c}0.02 \\
(0.68)\end{array}$ & $\begin{array}{c}0.44 \\
(0.54)\end{array}$ & $\begin{array}{c}0.20 \\
(0.47)\end{array}$ & $\begin{array}{l}-0.51 \\
(0.38)\end{array}$ & $\begin{array}{c}0.44 \\
(0.47)\end{array}$ & $\begin{array}{l}-0.73 \\
(0.56)\end{array}$ \\
\hline Divorced & $\begin{array}{c}0.15 \\
(0.32)\end{array}$ & $\begin{array}{c}0.53^{*} \\
(0.27)\end{array}$ & $\begin{array}{c}0.21 \\
(0.23)\end{array}$ & $\begin{array}{l}-0.20 \\
(0.23)\end{array}$ & $\begin{array}{l}0.46^{\star *} \\
(0.21)\end{array}$ & $\begin{array}{l}-0.33 \\
(0.25)\end{array}$ \\
\hline Widowed & $\begin{array}{l}0.61^{* * *} \\
(0.20)\end{array}$ & $\begin{array}{c}0.50^{*} \\
(0.26)\end{array}$ & $\begin{array}{l}0.75^{\star * *} \\
(0.10)\end{array}$ & $\begin{array}{l}0.87^{* * *} \\
(0.13)\end{array}$ & $\begin{array}{l}0.64^{* * *} \\
(0.07)\end{array}$ & $\begin{array}{l}0.68^{* * *} \\
(0.10)\end{array}$ \\
\hline \multicolumn{7}{|c|}{ Working status (Ref.: Retired) } \\
\hline Working & $\begin{array}{l}-0.07 \\
(0.10)\end{array}$ & $\begin{array}{c}0.10 \\
(0.08)\end{array}$ & $\begin{array}{c}0.00 \\
(0.07)\end{array}$ & $\begin{array}{c}0.02 \\
(0.06)\end{array}$ & $\begin{array}{l}-0.06 \\
(0.06)\end{array}$ & $\begin{array}{c}0.02 \\
(0.06)\end{array}$ \\
\hline Other & $\begin{array}{c}0.01 \\
(0.10)\end{array}$ & $\begin{array}{l}0.31^{\star * *} \\
(0.10)\end{array}$ & $\begin{array}{l}0.19^{\star \star *} \\
(0.06)\end{array}$ & $\begin{array}{l}0.20^{\star * *} \\
(0.07)\end{array}$ & $\begin{array}{c}0.08^{*} \\
(0.04)\end{array}$ & $\begin{array}{l}0.20^{* * *} \\
(0.07)\end{array}$ \\
\hline Diagnosed conditions & $\begin{array}{l}0.17^{\star * \star} \\
(0.06)\end{array}$ & $\begin{array}{l}0.22^{\star * *} \\
(0.06)\end{array}$ & $\begin{array}{l}0.38^{* * *} \\
(0.04)\end{array}$ & $\begin{array}{l}0.27^{\star * *} \\
(0.04)\end{array}$ & $\begin{array}{l}0.24^{* * *} \\
(0.03)\end{array}$ & $\begin{array}{l}0.15^{\star * *} \\
(0.04)\end{array}$ \\
\hline GALI $^{1}$ & $\begin{array}{l}0.54^{\star * *} \\
(0.06)\end{array}$ & $\begin{array}{l}0.37^{\star * *} \\
(0.06)\end{array}$ & $\begin{array}{l}0.50^{\star * *} \\
(0.04)\end{array}$ & $\begin{array}{l}0.45^{\star * *} \\
(0.04)\end{array}$ & $\begin{array}{l}0.39^{* * *} \\
(0.03)\end{array}$ & $\begin{array}{l}0.48^{* * *} \\
(0.04)\end{array}$ \\
\hline Constant & $\begin{array}{r}4.95^{*} \\
(2.58) \\
\end{array}$ & $\begin{array}{l}9.71^{* * *} \\
(2.22) \\
\end{array}$ & $\begin{array}{l}9.19^{* * *} \\
(1.44)\end{array}$ & $\begin{array}{l}9.12^{* * *} \\
(1.61)\end{array}$ & $\begin{array}{l}9.06^{* * *} \\
(1.10)\end{array}$ & $\begin{array}{l}7.99^{* * *} \\
(1.45)\end{array}$ \\
\hline $\mathrm{N}$ individuals & 9125 & 8775 & 18033 & 13095 & 20720 & 13047 \\
\hline $\mathrm{N}$ individuals $\mathrm{x}$ waves & 14601 & 14064 & 37871 & 26091 & 45584 & 27398 \\
\hline
\end{tabular}

Note: Estimated coefficients and standard errors (in parentheses) are reported. 1. GALI $=$ Global Activity Limitation Indicator. Significance level: *** $\mathrm{p}<0.01 ; * * \mathrm{p}<0.05 ; * \mathrm{p}<0.1$. 
Table A2: Percentage of respondents providing grandchild care on a (almost) daily basis, by country.

\begin{tabular}{lc}
\hline Country & \% daily grandchild care \\
\hline Denmark & 0.9 \\
Sweden & 1.2 \\
Netherlands & 1.5 \\
Switzerland & 2.0 \\
France & 4.2 \\
Germany & 4.5 \\
Estonia & 5.2 \\
Austria & 5.4 \\
Belgium & 6.9 \\
Czech Republic & 7.6 \\
Greece & 9.1 \\
Spain & 9.3 \\
Israel & 9.8 \\
Slovenia & 11.6 \\
Italy & 13.8 \\
Poland & 16.8 \\
\hline
\end{tabular}

